\title{
Conceptualizing Intersectionality between Work-family Conflict and Career Progress of Married Women Employed in Nepalese Financial Sector
}

\author{
Gaurav Ojha ${ }^{1}$ \\ ojhagaurav84@gmail.com
}

\begin{abstract}
This study examines the intersectional relationship between work-family conflict and career progress of married women employed in the financial sector within Kathmandu Valley. Although both work and family are important dimensions of human life, in Nepalese context the intersectional relationship between gender roles, work and family responsibilities and career progress has been inadequately studied. Hence, this research aims to conceptualize work-family conflict by examining the intersectional relationship between socio-demographic factors, antecedents of work-family conflict and career progress of married women employees in the context of Nepalese Financial Sector. In this study intersectional research design has been used to analyze relationships between variables together with ninety $(\mathrm{N}=90)$ married women employees as research participants. Results of both descriptive and inferential statistics indicate that asymmetry still remains prevalent and permeable among married women employees regarding their work-family interfaces and involvements. Hence, antecedents of work family conflict intersect a predictive association with subsequent existential experiences, ambition gaps and perceptions that negatively influences career progress of married women. Based on the findings, this study recommends a sustainable corporate culture and human resources management practices that remains sensitive to gender issues and also assimilates complex and conflicting necessities of both work and family involvements.
\end{abstract}

Keywords: Work-family conflict, Career progress, Sustainable corporate culture, Human resource practices

\footnotetext{
1 Gaurav Ojha is the Faculty at IEC College of Arts and Fashion. He is also the visiting Faculty of Sunway International Business School \& Kathmandu University School of Arts, Nepal.
} 


\section{Introduction}

\subsection{Background}

This study examines the intersectional relationship between work-family conflict and career progress of married women in the context of Nepalese financial sector. In Nepalese context, different studies have examined antecedents of work- life balance and work-family conflict and its potential consequences on career satisfaction, job satisfaction and well-being of employees in financial sector (Adhikary, 2018; Pathak, 2018; Acharya, \& Padmavathy, 2018). However, possibilities of differentiated understanding using an intersectional approach when it comes to conceptualizing work-family conflict by acknowledging distinct contextual experiences of being married, woman and employed in Nepalese financial sector remains as a research gap.

Moreover, the importance of the intersectional approach used in this study for analyzing work-family conflicts has been confirmed by the Gender Equality Index, 2019 published by European Institute for Gender Equality. As the survey exemplifies, certain groups of people, especially married women employees are expected to carry the double burden of work and family and are always at disadvantage in their search for reliefs from constant pressures of work-family conflict (Gender Equality Index, 2019).

Even with ever increasing inclusion of women as employees in Nepalese Financial sector regarding positions of top level managers, executives and leadership positions in these organizations, still women are discouragingly underrepresented. As evidence indicates according to Nepal labor force survey 2017/18 (Central Bureau of Statistics, 2019) human resource employed in financial services consists of 63,000 men and 55,000 women, hence in terms of percentage gender disparity only entails to $6.78 \%$, however when it comes to executive and leadership positions within financial sector gender disparity remains enormous and still there is a sharp contrasts between supply of women with relevant degrees in financial sector and executive position occupied by women employees.

More importantly, among different factors that influence married women's career advancement in an organizational context, as compared to men, women employees are perceived as having work-family conflict and these perceptions result in glass ceiling barriers regarding their career progress (Hoobler et al., 2009). More importantly, Hoobler et al. (2009) have indicated that both male and female top-level managers still perceive women employees as having greater family-work conflict and this perception has significant implications for career advancement of women employees. Therefore, it is necessary to conceptualize the prevalence of work-family conflicts within the experiences of married women employees. After all, the impact of work family conflict remains as a glass ceiling, potential stereotype and perceptual bias regarding their career progress.

Besides, in Nepalese context work family conflict is not perceived as a serious problem for a married woman because in a collectivist society dominated by masculine orientations regarding gender roles, women are expected to share the burden of family responsibilities exclusively (Hofstede et al., 2005). And, gender roles prevalent within Nepalese culture still 
categories women as responsible for family matters, hence exclusively incompatible with higher organizational roles and responsibilities.

In a survey conducted by McKinsey \& Company entitled closing the gap leadership perspectives on promoting women in financial services, nearly half of senior-level women say that they continue to accept most of household responsibilities, while just $13 \%$ of their male peers do the same. More importantly, as the survey indicates, women in entry-level roles in financial services seldom envision themselves in a top executive position and most of the entry-level women in financial services have concerns about balancing family and work commitment (Chin et al., 2018).

However, there is no study in Nepalese context that acknowledges gender inequalities within both work patterns and family structures where women before men are expected to carry the double burden of work and family. More importantly, this study examines contextual effects on work - family conflict incorporating a range of contextual demographic characteristics and intersectional experiences that subsequently results into negative perceptions and stereotypes regarding career progress of married women.

Besides, no other study has examined issues related with work-family conflict from the perspective of Sustainable Development Goal-5 that aims to overcome this leadership and empowerment gap by eliminating many root causes of gender discrimination and career progress barriers within both private and public spheres by 2030, and this study acknowledges work-family conflict as an important hindrance for career progress of married women employed.

\section{Literature Review and Theoretical Framework}

Different and considerable studies have examined, analyzed and evaluated work-family conflict experienced by women employees in different organizational contexts. This present study has also examined the restrictive effect of work-family conflict on career progress of married women employees in the context Nepalese Financial sector. For developing conceptual framework various theoretical frameworks and relevant/recent literature has been reviewed on time pressures, involvement misbalance and spill-over strains of family responsibilities on career progress of married women employees as antecedents of workfamily conflict.

\subsection{Theoretical framework}

Within a historical frame for conceptualizing work-family conflict, initially bounded theory recognized that women are more likely to experience inter-role conflict invoking incompatible demands from the work and family domains (Greenhaus, \& Beutell, 1985). Regarding spill-over strains of work family conflict, boundary theory by Pleck (1977) proposed that boundaries between work and family are asymmetrically permeable with unequal frequency and there are gender differences in the pattern of involvement. 
Similarly, regarding time pressures this study builds its theoretical orientations from the rational model, this model proposes that people who spend more time on either work or family domains may experience mutual propositions of conflict in each domain (Gutek et al., 1991). In addition, for involvement misbalance this study develops its theoretical foundations from role theory. Role theory also proposes that multiple roles lead to imbalance of involvement as it becomes more difficult to perform each role successfully, due to conflicting demands on time, lack of energy, or incompatible behaviors among roles (Greenhaus, \& Beutell, 1985).

Regarding, involvement imbalances and its stress, conservation of resources theory also explains stress outcomes for both inter-role stress, this model proposes that inter-role conflict leads to stress because resources are lost in the process of juggling both work and family roles (Wright, \& Cropanzano, 1998) and increasing female representation in Nepalese financial sector means that married women are juggling between their work and family roles and eventually this inter-role conflict creates constant condition of involvement imbalances for a married women.

\subsection{Review of related literature}

As a study succinctly mentions, the experience of work- family conflict for a married women may include a simple everyday existential realities such as not being able to pick up a child from daycare because of attending department meeting or not being able to go to work because one's children are sick (Cinamon, \& Rich, 2005). Similarly, a study states that time imbalance in work and family will make work-family conflicts arise if there is disequilibrium between distribution of time in parenting, family responsibilities and working in the organization (Vithanage, \& Arachchige, 2017).

Moreover, in a study, Lakmal and Gahan (2019) based on identity theory, concluded that crossover effects of work and family role imbalances were found to be more pronounced for women than men. Moreover, in a study Edwards and Rothbard (2000) have linked mechanisms between work and family and identified time as a finite resource, hence spending time in one life domain would automatically result in diminished time available to perform in another domain that subsequently results in constant time pressure. Recent studies in North American (Chin et al., 2018) and European context (Gender Equality Index, 2019) also indicate that asymmetry continues to exist between genders when it comes to sharing the burden of family responsibilities and family interference on work.

Similarly, Chincholkar and Krishna (2012) in a study on the work-family conflict among the married working executives in Greater Mumbai argued that women employees were acknowledging responsibilities than they would to deliver themselves in both domains and the article concluded that women need to redefine role expectations for themselves and their families. Similarly, in a study Hyman and Summers (2004) on financial sectors find that in the United Kingdom both direct and indirect work intrusions into domestic responsibilities of married employees. 
Moreover, Jogulu and Wood (2011) in a study regarding married women and their career progress as comparative study between Malaysia and Australia's middle managers indicate that women in two countries studied still have significant responsibilities for performing family duties, and bringing up children. In particular, the Malaysian respondents viewed family and personal responsibilities as their greatest impediment to attaining senior management positions. Besides, in a study, Valdez, and Gutek (1987) mention the career progression of working women will be affected due to work-family conflict.

Considering Nepalese literature on work-life conflict, Adhikary (2018) found nonsignificant, but positive correlation between work-family conflict and career satisfaction. However, the sample size of study consisted of 69 percent males and 31 percent females, whereas recent studies on work-family has recognized limitations of cross-sectional study when asymmetry and inequalities still remains permeable within the work and family role of a married woman (Gender Equality Index, 2019). Besides, in another study on barriers to career progression, Adhikary (2016) indicated that among different societal-related barriers, marriages during the prime of career significantly hampered the career development of Nepali women employees. This study also examines the relations between antecedents and outcomes of work-family conflict and its negative influence on career progress of married women in Nepalese financial sector

\subsection{Conceptual framework}

Acknowledging gender difference, asymmetrically permeability of work and family boundaries, and reciprocal as well as bidirectional nature of work-family conflict, this study has formulated a conceptual framework to examine influence of involvement imbalances time pressures and spill-over strains of work-family conflict on career progress of married women in the context of Nepalese Financial Sector (Greenhaus, \& Beutell, 1985;Edwards, \& Rothbard, 2003; Voydanoff, 2005; Vithanage, \& Arachchige, 2017).Moreover, this study has recognized bi-directional nature of the inter-role construct, therefore two distinct types of work-to-family conflict and family-to-work conflict are included in the framework. 


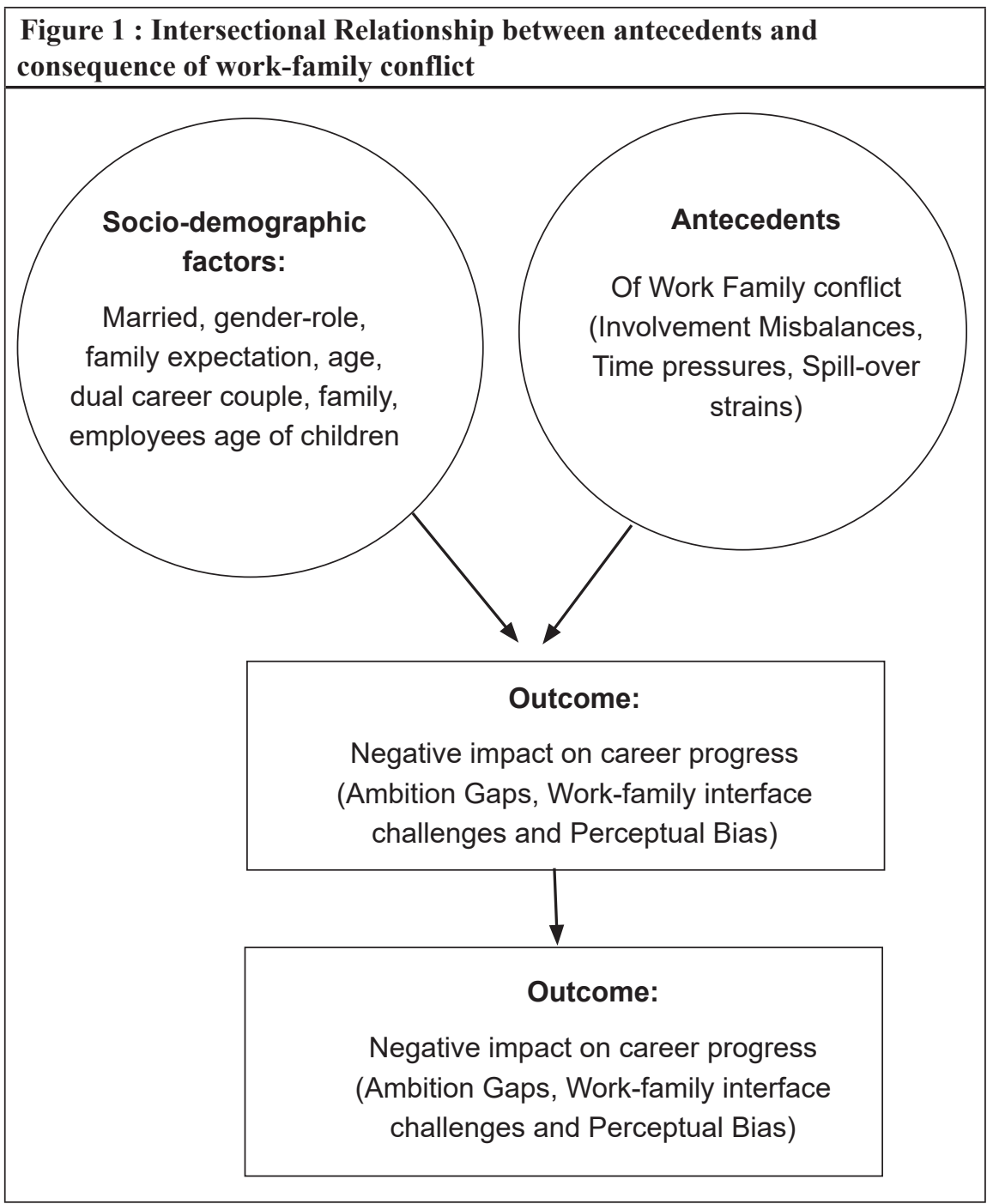

Based on the above conceptual framework this study was guided by the following research questions:

RQ1. To what extent do these factors as antecedents of work-family conflict (involvement misbalance, time pressures and spill-over strains) intersect with demographic factors and negatively influence the career of married women in the context of Nepalese Financial Sector?

RQ2. Are socio-demographic factors such gender-role, family expectation, age, dual career couple, family and age of children contributing factors to antecedents of work-family conflict and its subsequent outcome? 


\section{Research Design}

In this study intersectional quantitative design has been used for this study and intersectional approach to research indicates that different combinations can lead to different lived experiences of individuals in comparison to other individuals who might share one or more, but not all of the same elements (Christoffersen,2018). Methodological implications of intersectionality include the experiences of those at an intersection of multiple cultural, institutional and social positions that may not be accurately described by cross-sectional studies. This research design allows for framing social category such as gender using purposive sampling, to examine how measures demonstrate conceptual equivalence, measurement invariance and multiple level of intersectional even within a particular group (Else-Quest, \& Hyde, 2016)

\subsection{Participants and procedures}

In this study, a purposive sampling method has been used to locate 90 married women employees $(\mathrm{N}=90)$ of eight different commercial banks $(\mathrm{n}=60)$, two financial limited $(\mathrm{n}=10)$ and four insurance companies $(\mathrm{n}=20)$ within Kathmandu Valley were research participants. Data collection in this study involved a single-wave time-lag of six month and the data were collected by female interns (research students of the researcher) in these institutions using semi-structured questionnaires. Since, an intersectional approach to quantitative study is an emergent paradigm; it is explorative, qualitative in orientation and in-depth in analysis, besides it mainly focuses on revealing associations and differences (Christoffersen, 2018). Although this study has used descriptive statistics (percentage and frequency) and inferential statistics (chi-square, correlations and regression analysis) to analyze data and examine relationships between different factors, data presentation is more oriented towards thick description and in-depth study. In this study, Microsoft Excel, spreadsheet software with Analysis ToolPak has been used for data analysis.

\subsection{Instruments and measures}

Regarding, survey instruments included 16 items (4 for each variable) related to workfamily conflict and career progress (Cronbach's Alpha ranged from $=.756$ to .856 ), 8 items were for itemized scale ( 1 = Very Much to 4 = Very Little) question, 1 intersectional item for demographic factors as mentioned in research question (Agree/Disagree, Yes/No) and 6 items were associated with demographic. For measurement of variables Likert scale with $1=$ strongly agree and $5=$ strongly disagree was used. However, for the purpose of result reporting strongly agree and agree were combined together as agree and data from strongly disagree and disagree were combined as disagree. Hence, reporting only entails three scale items, agree, neutral and disagree. Furthermore, for developing survey instruments, regarding variable measurement was based on existing literature that was also used for developing conceptual framework. 


\section{Findings}

\subsection{Demographic information}

Demographic data from the survey indicate that of 90 married women $(\mathrm{N}=90)$ sampled for this study, $40 \%(n=36)$ of the respondent were under the age group of 30-40 age and 30\% $(n=27)$ were under the age group of 20-30 age and rest $(n=27)$ were in the age group of 40-50 and 50 above. Majority of research participants in this study have under-graduate or master's degrees $(80 \%, n=72)$ and $12 \%$ have master's in philosophy or doctoral degree $(n=11)$ and the rest $8 \%(\mathrm{n}=7)$ have completed high-school. Again, among married women employees approximately, $65 \%$ of respondents have management degrees and $25 \%$ have humanities and social science degrees and 10\% have computer related degrees. Approximately 50\% $(n=45)$ have work experience in the financial sector for 5-10 years, 20\% have less than 5 and remaining $30 \%$ are into the category of $10-15$ and above.

Table 1: Demographic Information

\begin{tabular}{|c|c|c|}
\hline Respondents character & $\begin{array}{c}\text { No. of } \\
\text { responses }\end{array}$ & $\begin{array}{c}\text { Percentage } \\
\text { (Approximately) }\end{array}$ \\
\hline Married Women (Employees in Financial Sector) & $\mathrm{N}=90$ & \\
\hline \multicolumn{3}{|c|}{ Age (in year) } \\
\hline $20-30$ & 36 & $40 \%$ \\
\hline $30-40$ & 27 & $30 \%$ \\
\hline $40-50$ & 17 & $18 \%$ \\
\hline 50 above & 10 & $12 \%$ \\
\hline Total & 90 & $100 \%$ \\
\hline \multicolumn{3}{|c|}{ Education } \\
\hline High School & 7 & $8 \%$ \\
\hline Bachelors (Under graduate) & 34 & $38 \%$ \\
\hline Post-Graduate & 38 & $42 \%$ \\
\hline MPhil. or PHD & 11 & $12 \%$ \\
\hline Total & 90 & $100 \%$ \\
\hline \multicolumn{3}{|c|}{ Degree } \\
\hline Management & 58 & $65 \%$ \\
\hline Humanities and Social Sciences & 23 & $25 \%$ \\
\hline ICT( Computer Science) & 9 & $10 \%$ \\
\hline Total & 90 & $100 \%$ \\
\hline
\end{tabular}




\begin{tabular}{|c|c|c|}
\hline Respondents character & $\begin{array}{c}\text { No. of } \\
\text { responses }\end{array}$ & $\begin{array}{c}\text { Percentage } \\
\text { (Approximately) }\end{array}$ \\
\hline \multicolumn{3}{|c|}{ Work Experience } \\
\hline Less than 5 years & 18 & $20 \%$ \\
\hline $5-10$ years & 45 & $50 \%$ \\
\hline $10-15$ years and above & 27 & $30 \%$ \\
\hline Total & 90 & $100 \%$ \\
\hline \multicolumn{3}{|c|}{ Organizational Hierarchy } \\
\hline Lower Level & 9 & $10 \%$ \\
\hline Middle Level & 68 & $75 \%$ \\
\hline Senior Management & 13 & $15 \%$ \\
\hline Total & 90 & $100 \%$ \\
\hline \multicolumn{3}{|c|}{ Dual Career Couples } \\
\hline Dual Career Couples & 68 & $75 \%$ \\
\hline Non-Dual Career Couples & 22 & $25 \%$ \\
\hline Total & 90 & $100 \%$ \\
\hline \multicolumn{3}{|c|}{ Family Structure } \\
\hline Nuclear Family & 54 & $60 \%$ \\
\hline Joint Family & 36 & $40 \%$ \\
\hline Total & 90 & $100 \%$ \\
\hline \multicolumn{3}{|c|}{ Number of Children } \\
\hline Without any Child & 23 & $25 \%$ \\
\hline 1 Child & 49 & $55 \%$ \\
\hline 2 or more that two children & 18 & $20 \%$ \\
\hline Total & 90 & $100 \%$ \\
\hline
\end{tabular}

Of sample married employee $(\mathrm{N}=90)$ within organizational hierarchy $15 \%(n=13)$ are in senior management position, approximately $75 \%(n=68)$ on middle-level \& lower level and $10 \%(n=9)$ in non-managerial position and this demographic data regarding organizational position also exemplifies the findings of a discussion note published by IMF that has identified large gaps between the representation of men and women in leadership positions in banks and in banking-supervision agencies worldwide (Sahay, \& Cihak, 2018). Similarly, the study finds that approximately $75 \%(\mathrm{n}=68)$ women employees are dual career couples and in $65 \%(n=58)$ families both mom and dad work full time.

Regarding family structure, majority of respondents are part of nuclear family $(60 \%, n=54)$ and rest $40 \%,(n=36)$ belonged to joint family and concerning children, $55 \%(\mathrm{~N}=49)$ of sample married women are with one child, $25 \%$ of them are without any child and rest $20 \%$ have 2 or more than two children. Similarly, approximately $90 \%(n=81)$ of married women with children are using child-care centers and pre-school for their child under age 
of 6 and the rest of them, 30\% $(n=24)$ are using in-home care. Besides, approximately $45 \%$ $(n=41)$ of respondents indicate that they have used child-care centers for their child within 6-15 months of age and majority of respondents, $70 \%(n=63)$ of them fall under the 30-40 age group.

\subsection{Responses on perceived intersectional demographic factors}

Similarly, regarding the question of the negative impact of work- family conflict on their career progress, $80 \%(n=29)$ of married women in the age group of 30-40 indicate much or very much, approximately $60 \%(\mathrm{n}=17)$ of women in 20 -30 age groups also indicate the same. After all, combining these two age groups as earlier study also concludes, employees within this life-stage are likely to be working longer hours and trying to define their professionalism and considering their lifespan they are also more likely to start a family and have more responsibilities such as having young children at home and this results into greater work-life conflicts (Voydanoff, 2005).

Consequently, on the issue of gender differences, $78 \%(n=70)$ of participants have responded in the range of very much and much that asymmetry still continues to exist between men and women in work and family roles and being a woman contributes to their experience of work-family conflict. In addition, regarding comparative rank question on influence of work and family demands, $60 \%$ of participants $(n=54)$ responded that expectation of family has greater impact on their career progress than work and this finding relates with a study by Choi (2008) that work and family demands cause life stress among Chinese employees and the effect of family demands on life stress is mediated by work-family conflict.

Approximately $80 \%(n=72)$ of married women indicate very much or much regarding their involvement in domestic responsibilities more than their husband. Similarly, regarding the response on do you consider challenges of work-family interference have resulted into an ambition gap regarding your career progress, approximately $70 \%(n=63)$, identify very much and much. Here, comparable with findings of Chin et al., (2018), this study also explores that the challenge of balancing work family conflict results in ambition gaps for a married woman employee.

Table 2: Responses on Perceived Intersectional Demographic Factors

\begin{tabular}{|l|c|c|}
\hline Responses & No. of responses & $\begin{array}{c}\text { Percentage } \\
\text { (Approximately) }\end{array}$ \\
\hline 1. Negative impact of work- family conflict on career progress (Age Group Response) \\
\hline 20-30 Age Group (Much/Very Much) & $29(\mathrm{~N}=36)$ & $80 \%$ \\
\hline 30-40 Age Group (Much/Very Much) & $17(\mathrm{~N}=27)$ & $60 \%$ \\
\hline 40-50 Age Group (Much/Very Much) & $7(\mathrm{~N}=17)$ & $42 \%$ \\
\hline 50 above (Much/Very Much) & $2(\mathrm{~N}=10)$ & $20 \%$ \\
\hline 2. Gender differences and experience of asymmetry in Work and Family Roles \\
\hline
\end{tabular}




\begin{tabular}{|c|c|c|}
\hline Responses & No. of responses & $\begin{array}{c}\text { Percentage } \\
\text { (Approximately) }\end{array}$ \\
\hline Very Much/Much & 70 & $78 \%$ \\
\hline Little/Very Little & 20 & $22 \%$ \\
\hline Total & $\mathrm{N}=90$ & $100 \%$ \\
\hline \multicolumn{3}{|c|}{ 3. Impact of Family Expectation on Career Progress } \\
\hline Greater Impact/Impact & 54 & $60 \%$ \\
\hline Lesser Impact/No Impact & 36 & $40 \%$ \\
\hline Total & $\mathrm{N}=90$ & $100 \%$ \\
\hline \multicolumn{3}{|c|}{ 4. Domestic Involvement Compared to Husband } \\
\hline More Involvement than Husband & 72 & $80 \%$ \\
\hline Equal or Less Involvement than Husband & 18 & $20 \%$ \\
\hline Total & $\mathrm{N}=90$ & $100 \%$ \\
\hline \multicolumn{3}{|c|}{$\begin{array}{l}\text { 5. Do you think gender marital status, dual career spouse and age of your child have contributed } \\
\text { to your experiences of work family conflict? (Intersectional demographic Variables) }\end{array}$} \\
\hline Disagree & 20 & $22 \%$ \\
\hline Agree & 70 & $78 \%$ \\
\hline Total & $\mathrm{N}=90$ & $100 \%$ \\
\hline \multicolumn{3}{|c|}{ 6. Restriction of Work Family Conflict on Career Progress } \\
\hline Yes & 68 & $75 \%$ \\
\hline No & 22 & $25 \%$ \\
\hline Total & $\mathrm{N}=90$ & $100 \%$ \\
\hline
\end{tabular}

Moreover, when it comes to intersectional influence between demographic factors such gender, dual career spouse and age of child (do you think your gender marital status, dual career spouse and age of your child has contributed to your experiences of work family conflict) as contributing factors to antecedents of work-family conflict ,approximately $78 \%$ $(n=70)$ of respondents agree that demographic factors as contributing factors to antecedents of work-family conflict and its subsequent outcomes. Besides, approximately $75 \%(n=68)$ agree that work-family conflict can potentially restrict their career progress after all women are more involved in family activities while at the same time also accumulating their professional work (Greenhaus, \& Powell, 2012). 


\subsection{Correlation analysis}

Table 3: Correlation Statistics of Intersectional Demographic factors with Workfamily conflict $\&$ its subsequent impact on career progress

\begin{tabular}{|c|c|c|}
\hline $\begin{array}{l}\text { Socio-demographic Variables } \\
(\mathrm{N}=90)\end{array}$ & & $\begin{array}{c}\text { Work-family conflict \& its subsequent } \\
\text { impact on career progress }\end{array}$ \\
\hline \multirow[t]{3}{*}{ Gender Difference } & Pearson Correlation & $0.78^{*}$ \\
\hline & Sig. (2-tailed) & 0.025 \\
\hline & $\mathrm{N}$ & 90 \\
\hline \multirow[t]{3}{*}{ Dual career couple } & Pearson Correlation & $0.72 *$ \\
\hline & Sig. (2-tailed) & 0.020 \\
\hline & $\mathrm{N}$ & 90 \\
\hline \multirow{3}{*}{ Age of youngest children } & Pearson Correlation & 0.12 \\
\hline & Sig. (2-tailed) & 0.44 \\
\hline & $\mathrm{N}$ & 90 \\
\hline \multirow[t]{3}{*}{ Family expectations } & Pearson Correlation & $0.67 *$ \\
\hline & Sig. (2-tailed) & 0.032 \\
\hline & $\mathrm{N}$ & 90 \\
\hline \multicolumn{3}{|c|}{$\begin{array}{l}\text { * Correlation is significant at the } 05 \text { level (2-tailed) (Note: Perceptions on } \\
\text { Demographic factors and Work-family conflict (itemized Scale } 1=\text { very much to } 4= \\
\text { very little), }\end{array}$} \\
\hline
\end{tabular}

Similarly, Person's correlation also indicates a positive relation $(\mathrm{r}=0.78, \mathrm{P}=0.025)$ between negative impact of work-family conflict on career progress (Do you think work-family conflict negatively influences your career progress) and gender difference (Do you think your gender roles influence your experience of work-family conflict). Similarly there is a positive and significant relationship between being a dual career couple $(\mathrm{r}=0.72, \mathrm{P}=0.020)$, regarding age of youngest child $(\mathrm{r}=0.12, \mathrm{P}=0.44)$ there is statistically insignificant and weak positive correlation. Likewise, regarding child and parent role, a study found that women find their child as central to their identity and give more importance to parental role (Gaunt $\&$ Scott, 2017). Hence, married women find it difficult to consider the age of their child as a burden. Regarding family expectations, this factor has a positive and significant relationship with work family conflict $(\mathrm{r}=0.67, \mathrm{P}=0.032)$.

\subsection{Chi-Square analysis of variations in work family}

In this study to investigate differences of response regarding work-family conflict based on age-group differences chi-square analysis has been conducted. Pearson chi-square results indicate that there is significant difference in responses of participants based on their age 
group. Regarding age, approximately $80 \%(n=29)$ of women in the age range of 30-40 age group and $60 \%(n=20-30)$ indicate their current age group as an important factor that influences their work family conflict and also their concerns about career progress. Therefore, this study has evaluated a statistically significant degree of difference among demographic factors (age) and its association with work-family conflict. After all, a study indicates that the relationship between gender and work-life conflict is significantly moderated by age (Cloninger et al., 2015).

Table-4: Chi-Square Analysis of variations in Work family conflict among married women based on their age group

\begin{tabular}{|l|l|l|}
\hline Variable & Age group (N=90) & $X^{2}$ P-value \\
\hline $\begin{array}{l}\text { Prevalence of Work-Family } \\
\text { conflict and its subsequent }\end{array}$ & $\begin{array}{l}-20-30(60 \% \text { - Very Much/Much }) \\
\text { Influence }\end{array}$ & $30-40(80 \%$-Very Much/Much $)-40-50$ \\
& $\begin{array}{l}\text { (57\%-Very Much/Much) } \\
-50 \text { and Above (34\% Very Much/Much) }\end{array}$ & \\
\hline
\end{tabular}

$N=$ number of participants, $P$ value significant at 0.05 (2-tailed)

Moreover, similar to the chi-square analysis in this study, other studies also indicate that younger married employees experience distress as a result of interference between work and family involvement and the employees in middle adulthood experience highest levels of interference (Bellavia, \& Frone, 2005). Likewise, in a study Huffman et al. (2013) indicate that relationship between family conflict and age is curvilinear in nature; their study finds that work-family conflict was lowest for younger and older workers, and highest for workers in the middle age group.

\subsection{Regression Analysis for predicting work-life conflict career progress}

Table 5 : Regression Analysis for predicting work-life conflict and its negative impact on career progress of married woman

\begin{tabular}{|l|l|c|c|c|c|c|}
\hline \multirow{2}{*}{ Model } & \multicolumn{2}{|c|}{$\begin{array}{c}\text { Unstandardized } \\
\text { Coefficients }\end{array}$} & $\begin{array}{c}\text { Standardized } \\
\text { Coefficients }\end{array}$ & \multirow{2}{*}{ t value } & \multirow{2}{*}{ Sig. } \\
\cline { 2 - 7 } & Beta & Std. Error & Beta & & \\
\hline \multirow{2}{*}{1} & 2.89 & .136 & & 5.15 & $.010^{*}$ \\
\cline { 2 - 7 } & $\begin{array}{l}\text { (Constant) } \\
\text { Involvement } \\
\text { imbalances }\end{array}$ & 0.260 & .049 & 0.289 & 8.73 & $.0234^{*}$ \\
\cline { 2 - 7 } & Time Pressures & 0.343 & .067 & 0.369 & 2.45 & $.023^{*}$ \\
\cline { 2 - 7 } & Spill-Over Strains & 0.173 & .069 & 0.181 & 3.53 & $.011^{*}$ \\
\hline
\end{tabular}

*.Significant at the 0.05 level, $R 2=0.68, F=33.032, p<.05 \beta=$ Standardized Regression Coefficient, * $p<.05$ 
The results of regression analysis indicates significant predictive of gains in work-life conflict due to involvement imbalances time pressures and spill-over strain $r^{2}=.68$, and $r^{2}$ adj $=.61, \mathrm{~F}=33.32, \mathrm{p}=.020$. Therefore, this model predicts $68 \%$ variation in antecedents of work family conflict increases barriers to career progress among married women in Nepalese financial sector. In this model all variables were included in the equation including career progress and work-life conflict. As the analysis predicts these antecedents of work family conflict negatively spills over as a barrier for career progress of married women.

Since standardized $\beta$ s are positive, based on regression analysis this study indicates that 1 percent enhance in involvement imbalances, time pressures and spill-over strains, normally, and has the positive relationship influence of a rising work-family conflict that results in hindrance for the career progress of a married woman. Regression analysis of this study confirms the model of Greenhaus and Beutell (1985), which recognizes time, strain and involvement imbalances as sources of work-family conflict.

As comparable to findings, another study has also indicated that as the employed mother is experiencing time pressures in work and family roles then the motivation to advance her career diminish (Bartolome \& Evans, 1979). Regarding involvement imbalances and its stress, conservation of resources theory also explains stress outcomes of inter-role imbalances results in a negative state of being (Grandey, \& Cropanzano, 1999) that culminate into lack of interest in career development.

\section{Discussions}

In this study, descriptive and inferential results indicate an intersectional relationship between different socio-demographic factors such gender-role, family expectation, age, dual career couple and age of children and work-family, and the result of descriptive, correlation and chi-square analysis are comparable with studies that have been conducted in South Asian Context (Jain \& Nair, 2016; Rajadhyaksha, \& Velgach 2009; Buddhapriya, 2009) and consistent with other studies that have considered moderating role of socio-demographic factors on work-family conflict (Pleck, 1977; Byron, 2005).

In a study related to examining antecedents of work-life conflict Byron (2005) mentioned that demographic variables, such as gender and marital status are predictors of workfamily conflict work-family conflict. Similarly, comparable with the findings of this study, Buddhapriya (2009) indicated family responsibilities of married women negatively affect their career advancement to senior positions, as they experience career tradeoffs and imbalances of involvement between professional roles because of the family responsibilities.

Descriptive analysis of the study indicates that among sample married women within organizational hierarchy $15 \%$ are in senior management position and this find is comparable to a study by Chin et al. (2018) research shows that women remain significantly underrepresented in the upper levels of financial-services companies and even in Northern American Context, women account for only $19 \%$ of leadership positions. Hence, despite 
this growth of employment opportunities for women in Nepalese financial sector, regarding leadership, senior managerial and senior professional roles, gender disparity remains extremely high (Ross-Smith, \& McGraw, 2010).

Moreover, this study finds that career decisions of married women employee, predominantly guided by the demands of family care and they experience negative spill-over effects of work-family conflict on their career. And, this asymmetric remains consistent even in this study and also comparable to findings by Abeysekera and Gahan (2019) that the impact of crossover effects of work-family conflicts was found to be more pronounced for women. Besides, as socio-demographic variables associated with family domain and presence of antecedents of work-family conflict in both professional and family role of a married woman indicate that ambition gap persists even among married women employee because of their inability to balance family and due to this major reason they are not pursuing top executive roles (Chin et al., 2018). After all, based on the findings of inferential statistics, this study also concludes that an employee experiencing strains of work family conflict is less likely to participate or take initiatives for career development (Higgins et al., 1992)

More importantly, Hoobler et al. (2009) consider work-family conflict as a main hurdle for career progress of a married women employee since top-level management perceives women having greater family-work conflict and therefore view them as mismatched for leadership roles in an organization. And, due to asymmetrical involvement in both work and family domains, there is a tendency among top-level managers to perceive women employees as experiencing greater family-work conflict. Therefore, mismatched for career advancements and leadership fits within the working style of the financial sector that recognizes long hours as organizational commitment, besides it is difficult for married women to balance the conflicts arising from work and family spheres (Lockwood, 2003). After all, this study also indicates that balancing work and family conflict is both experientially and existentially difficult for employed married women.

\section{Conclusion and Recommendations}

Taking findings and discussions into consideration, this study concludes that married women are experiencing work-family conflict that has a negative influence on their career development. As Sustainable Development Goal-5 also argues for inclusive policies concerning greater gender equality when it comes to career progress of female employee, this study also indicates that work-family concept still remains as a challenge, due to gendered division of work and family responsibilities and asymmetrically permeable family and work roles prevalent among Nepalese married women and these realities have habitually culminate into negative stereotypes, perceptual bias and subsequent glass ceiling.

Moreover, this study recommends a need for sustainable corporate culture and human resource practices which acknowledges diversity, family supportive cultures, and gender issues and assimilates complex and conflicting necessities of both work and family. Besides, this study 
recommends organizations to realize that work and family are interrelated domains, and strains experienced in each domains have a mutual impact on another (Kalliath et al.,2012). More importantly, gender inequalities in work-family balance decreases opportunities for career progress among married woman (Sullivan, 2019)

This article also recommends that organizations need to introduce family-friendly policies, flexible work arrangements, compressed workweek plans and cultivate a family-supportive organizational culture to ensure that married women employees have the necessary family supportive programs. Besides, organizations need supportive resources for those employees who are most in need for balancing work-family interfaces (Mansour, \& Tremblay, 2018). And, to reduce stress associated with work-family conflict, it is also necessary for organizations to incorporate policies that facilitate work-family enrichment (Jain, \& Nair, 2020). Besides, it is necessary for organizations to develop systematic and robust organization-based approach to provide solution for work-family conflict within financial institutions especially for married female employees (Ajayi et al., 2020)

Moreover, recent study indicates that clarifying priorities between work and family roles may result into lesser work family conflict (Erdogan et al., 2019) Therefore, concerning married women, this study recommends them to become better with role segmentation, seek colleague support, negotiate for flexible work arrangements, have enough courage to overcome social criticisms and disapprovals, cultivate highly impermeable and inflexibly role boundaries between work and family domain. 


\section{References}

Abeysekera, L., \& Gahan, P. (2019). Work-family conflict among Australian dual-earner couples: Testing the effects of role salience crossover and gender. The International Journal of Human Resource Management, 30(10), 1549-1582.

Acharya, A., \&Padmavathy, G. (2018). Work life balance and job satisfaction: A study from private banks of Nepal. International Journal for Advance Research and Development, 3(12), 33-37.

Adhikary, J. R. (2018). Work Family Conflict and Career Satisfaction: Role of Social Support, $N R B$ Economic Review.30(1), 69-96.

Adhikary, J. R. (2016). Barriers to career progression: a study of the perceptions of Nepali women employees. Journal of Business and Management Research, 1(2), 17-32.

Ajayi, M. P., Olawande, T. I., Jegede, A. E., Amoo, E. O., \& Olawole-Isaac, A. (2020). Workfamily conflict: Evaluating the mediating role of personal intervening strategies. Cogent Social Sciences, 6(1), 1731224.

Bartolomé, F., \& Evans, P. A. L. (1979). Professional lives versus private lives-shifting patterns of managerial commitment. Organizational Dynamics, 7(4), 3-29.

Bellavia, G. M. (2005). Work-family conflict. I J. Barling, EK Kelloway \& MR Frone (Red.) Handbook of Work Stress (s. 113-147).

Buddhapriya, S. (2009). Work-family challenges and their impact on career decisions: A study of Indian women professionals. Vikalpa, 34(1), 31-46.

Byron, K. (2005). A meta-analytic review of work-family conflict and its antecedents. Journal of Vocational Behavior, 67(2), 169-198.

Central Bureau of Statistics. (2019) Report on Nepal Labor Force Survey, 2017/18.Kathmandu, Nepal: CBS Chincholkar, S., \& Krishna, N. (2012). Work-Family Conflict of Married Women Business Executives in Mumbai. SIES Journal of management, 8(2).

Chin S., Nadeau M., \&Krivkovich A. (2018). Closing the gaps in perspectives on promoting women in financial services. Global Banking Practice. New York:McKinsey and Company

Choi, J. (2008). Work and family demands and life stress among Chinese employees: The mediating effect of work-family conflict: Work and family demands and life stress among Chinese employees: The mediating effect of work-family conflict. The International Journal of Human Resource Management, 19(5), 878-895.

Christoffersen, A. (2018). Researching Intersectionality: Ethical Issues: Jo Campling Essay Prize, Postgraduate Winner, 2018. Ethics and Social Welfare, 12(4), 414-421.

Cinamon, R. G., \& Rich, Y. (2005). Work-family conflict among female teachers. Teaching and Teacher Education, 21(4), 365-378.

Cloninger, P. A., Selvarajan, T. T., Singh, B., \& Huang, S. (2015). The mediating influence of work-family conflict and the moderating influence of gender on employee outcomes. The Journal of Human Resource Management, 26(18), 2269-2287.

Edwards, J. R., \& Rothbard, N. P. (2000). Mechanisms linking work and family: Clarifying the relationship between work and family constructs. Academy of management review, 25(1), 178- 199.

Else-Quest, N. M., \& Hyde, J. S. (2016). Intersectionality in quantitative psychological research: I. Theoretical and epistemological issues. Psychology of Women Quarterly, 40(2), 155-170. 
Erdogan, I., Ozcelik, H., \& Bagger, J. (2019). Roles and work-family conflict: how role salience and gender comes into play. The International Journal of Human Resource Management, 8(23), 1-23

Grandey, A. A., \&Cropanzano, R. (1999). The conservation of resources model applied to work-family conflict and strain. Journal of Vocational Behavior, 54(2), 350-370.

Greenhaus, J. H., \& Beutell, N. J. (1985). Sources of conflict between work and family roles. Academy of management review, 10(1), 76-88.

Greenhaus, J. H., \& Powell, G. N. (2012). The family-relatedness of work decisions: A framework and agenda for theory and research. Journal of vocational behavior, 80(2), 246-255.

Gutek, B. A., Searle, S., \& Klepa, L. (1991). Rational versus gender role explanations for work-family conflict. Journal of applied psychology, 76(4), 560.

Higgins, C. A., Duxbury, L. E., \& Irving, R. H. (1992). Work-family conflict in the dual-career family. Organizational Behavior and Human Decision Processes, 51(1), 51-75.

Hofstede, G., Hofstede, G. J., \&Minkov, M. (2005). Cultures and organizations: Software of the mind (Vol. 2). New York: Mcgraw-hill.

Hoobler, J. M., Wayne, S. J., \& Lemmon, G. (2009). Bosses' perceptions of family-work conflict and women's promotability: Glass ceiling effects. Academy of management journal, 52(5), 939-957.

Huffman, A., S. Culbertson, S., B. Henning, J., \& Goh, A. (2013). Work-family conflict across the lifespan. Journal of Managerial Psychology, 28 (7/8), 761-780.

Index, G. E. Work-life balance (2019) European Institute for Gender Equality (EIGE -Gender EqualityIndex-2019).

Jain, S., \& Nair, S. K. (2016). Work-Family Conflict in India: Construct Validation and Current Status. Asia-Pacific Journal of Management Research and Innovation, 12(1), 31-45.

Jain, S., \& Nair, S. K. (2020). Integrating work-family conflict and enrichment: understanding the moderating role of demographic variables. International Journal of Organizational Analysis. 28 (2), 23-31.

Jogulu, U., \& Wood, G. (2011). Women managers' career progression: an Asia Pacific perspective. Gender in Management: An International Journal, 26(8), 590-603.

Kalliath, P., Hughes, M., \& Newcombe, P. (2012). When work and family are in conflict: Impact on psychological strain experienced by social workers in Australia. Australian Social Work, 65(3), 355-371.

Lockwood, N. R. (2003). Work/life balance. Challenges and Solutions, SHRM Research, USA.

Mansour, S., \& Tremblay, D. G. (2018). Work-family conflict/family-work conflict, job stress, burnout and intention to leave in the hotel industry in Quebec (Canada): moderating role of need for family friendly practices as "resource passageways", The International Journal of Human Resource Management, 29(16), 2399-2430.

Pathak, R. R. (2018). Work Life Balance in Nepalese Commercial Banks. Journal of Business and Social Sciences, 2(1), 116-125.

Phipps, S., Burton, P., \& Osberg, L. (2001). Time as a source of inequality within marriage: are husbands more satisfied with time for themselves than wives? Feminist economics, 7(2), 1-21

Pleck, J. H. (1977). The work-family role system. Social problems, 24(4), 417-427.

Rajadhyaksha, U., \&Velgach, S. (2009, May). Gender, gender role ideology and work-family conflict in India. In Academy of Management Annual Meeting (pp. 1-40). 
Ross-Smith, A., \& McGraw, P. (2010). EOWA 2010: Australian census of women in leadership: research conducted by Macquarie University, supported by ANZ.

Sahay, M. R., \& Cihak, M. M. (2018). Women in Finance: A Case for Closing Gaps.

International Monetary Fund. Sullivan, O. (2019). Gender inequality in work-family balance. Nature Human Behaviour, 3(3), 201-203.

Valdez, R. L., \& Gutek, B. A. (1987). Family roles: A help or hindrance for working women? In B. A. Gutek \& L. Larwood (Eds.), Women's career development (pp. 157-169). Newbury Park, CA: Sage.

Vithanage, V., \& Arachchige, B. J. (2017). A study on the work-family balance and job performance of academics in Sri Lanka. IUP Journal of Management Research, 16(2), 7-18.

Voydanoff, P. (2005). Consequences of boundary-spanning demands and resources for work-to-family conflict and perceived stress. Journal of occupational health psychology, 10(4), 491-505.

Wright, T. A., \&Cropanzano, R. (1998). Emotional exhaustion as a predictor of job performance and voluntary turnover. Journal of applied psychology, 83(3), 486. 